\title{
¿Qué significa aprender desde Proyectos de Indagación? ${ }^{1}$
}

Lutiere Dalla Valle ${ }^{2}$

\begin{abstract}
Resumen
El entrelazamiento entre Cine y Educación es el punto dónde he partido para la construcción de esta investigación. A través de indagaciones desarrolladas en una signatura del curso de Licenciatura dado por Fernando Hernández (Historia y Curriculum de Educación Artística de la Universidad de Barcelona/ BBAA/ UB/ ES) y a partir de la película francesa "Entre les Murs" y los Proyectos de Indagación construidos por las estudiantes del Curso. Los elementos que desde allí surgieron nos sirven para pensar otras formas de investigación y construcción de conocimientos en la academia. Tomando por base la Perspectiva Construccionista y de los Estudios de la Cultura Visual a partir de Proyectos de Trabajo, el objetivo principal de este labor fue saber qué significa aprender desde Proyectos de Indagación, desde el cine y qué aportaciones a los Estudios de la Cultura Visual podremos tejer. De esta manera, tomando parte de las Pedagogías Culturales, Educación de la Cultura Visual y Prácticas Artísticas Colaborativas, lo que presento es un recogido del proceso desarrollado y un análisis de lo vivido/construido.
\end{abstract}

Palabras clave: Proyectos de Indagación - Proyectos de Trabajo - Aprendizaje

Colaborativo - Cine - Educación

\section{What means to learn from Projects of Investigation?}

\begin{abstract}
The interweaving between Cinema and Education is the point where I have left to the construction of this investigation. Through investigations developed in a signature of the course of Degree given by Fernando Hernandez (History and Curriculum of Artistic Education of the University of Barcelona BBAA/UB/ES) and from the French film "Entre les Murs" and the Projects of Investigation constructed by the students of the Course, the elements that thence arose serve us to think other forms of investigation and construction of knowledge about the academy. Taking by base the Construccionista Perspective and from the Visual Culture Studies from Projects of Work, the primary target of this work was to know what means to learn from Projects of Investigation from the cinema and what contributions to Visual Culture Studies. This way, taking part from the Pedagogies Cultural and Education of Artistic the Visual Culture and Practical Collaborative, which I present is gathered of the developed process and an analysis of the constructed lived thing.
\end{abstract}

Key words: Projects of Investigation - Projects of Work - Collaborative learning -

Cinema - Education

\footnotetext{
${ }^{1}$ Parte de la investigación desarrollada para el Máster Oficial en Educación y Artes Visuales: Un Enfoque Construccionista/ BBAA/ Universidad de Barcelona - 2008/2009 bajo la tutoría de Fernando Hernández.

2 Doctorando en Educación y Artes - Universidad de Barcelona (2010), Máster en Educación y Artes Visuales (2009/BBAA/BCN/ES), Máster en Educación (2008/UFSM/RS/BR). luthiere@terra.com.br
} 
Potser el desig d'aprendre és la font que ens empeny a emprendre un viatge, a seguir un procés per a conèixer i contar una història. I així ens plantegem aquest projecte. Caminarem plegades, amb l'objectiu final d'explicar-vos a tots i a totes una història, la nostra història de com hem après traçant trajectes pels camins del desig i de I'aprendre.

(Miriam Grau - Estudiante de BBAA)

Reflejar "desde mí" lo que ocurre a mi lado desde perspectivas que contemplan lo que creo y lo que me construye como sujeto (mi propia historia personal, mis recuerdos, mi contexto social, cultural y familiar), pensar el mundo y las relaciones sociales que se hacen presentes al entorno desde una mirada personal, crítica y reflexiva parece ser uno de los puntos más fuertes en el proceso que he experimentado recientemente. Además de eso, establecer relaciones que puedan servir a la construcción de conocimientos, desde lo vivido y las propias dudas también son ideas que creo puedan ser tomadas como estrategias o herramientas importantes y necesarias para el aprendizaje de nuestra actualidad.

Es cierto que durante la vida escolar (e incluso la académica) normalmente lo que he observado (y vivenciado) es que los estudiantes empiezan a hablar desde otras personas, desde puntos de vista de los historiadores, de los teóricos, de la gente que tiene "el poder" y que decide lo que se debe pensar, lo que es correcto y verdadero. En general nadie se les (nos) pregunta o les (nos) hace pensar que los cuestionamientos particulares pueden ser útiles para desencadenar proyectos de indagación y de construcción de conocimientos más amplios y significativos. Casi siempre la idea de construcción de los conocimientos es más bien algo que viene "desde fuera", que parte de aquello que fue seleccionado por alguien y que debe ser aceptado como única forma de construcción. Sin embargo, lo que ha pasado en este último año desde que empecé el máster en la Universidad de Barcelona (igualmente en el Curso de Historia y Curriculum dónde he desarrollado mi investigación) fue exactamente lo contrario: el principal eje fue hablar "desde si(mi) mismo", desde lo que uno relaciona, desde lo que construye, desde lo que ve, de lo que selecciona, desde lo que se les afecta y tiene significado.

Con el sentido de abrirse a otras lógicas de investigación que no siguen exactamente los modelos académicos instituidos y que puedan ofrecer maneras distintas de acercarse de lo que se plantea investigar es que se ha pensado en este trabajo. Aprender desde el cine y desde la indagación a partir de una perspectiva de aprendizaje colaborativo donde cada uno pueda encontrar su lugar para aprender y todos y todas puedan contribuir y 
hacer visible lo que se los afecta es por donde he(mos) hecho nuestro "viaje" en el Curso de Historia y Curriculum de BBAA.

Por lo tanto, en esta investigación me interesaba saber cómo se construye la relación entre la indagación particular y la construcción del conocimiento a partir de los Proyectos de Indagación desarrollados por un grupo de estudiantes en proceso de formación docente en la Universidad de Barcelona teniendo en cuenta el cine como punto de partida y el Enfoque Construccionista de los Estudios de la Cultura Visual y de la Investigación Basada en las Artes como marco teórico y conceptual.

El interés en tener el cine como eje para el desarrollo de Proyectos de Indagación me acompaña desde hace cerca de un año cuando en una discusión con mis alumnos adolescentes en clase de Educación Artística íbamos a buscar en el cine el punto de partida para desarrollar nuestra planificación del curso. Motivados por las imágenes fílmicas que eran muy presentes en nuestro cotidiano empezamos a descubrir juntos sus posibilidades de entrecruzamientos con los contenidos de las Artes Visuales y lo que podría emergir desde ahí. Hicimos algunas aproximaciones, construimos algunos trabajos "desde fuera", pero de manera no tan profundizadas incluso porque para nosotros era un camino nuevo a ser descubierto. Al final del proceso, me he dado cuenta de que la vía que hubiéramos escogido podría ser el comienzo de una forma distinta de trabajar los contenidos formales y obligatorios de la escuela desde otro punto de vista.

De estas vivencias, en aquellos momentos de experimentación y aproximación con el cine, en un primer momento no había sido consciente de la importancia que tendría estas conexiones con la educación en mi posterior (y actual) trayectoria como investigador en el campo de los Estudios de la Cultura Visual.

Aún en Brasil, estaba yo al final de la escritura de mi tesina de máster en Educación en la Universidad Federal de Santa María investigando sobre las Representaciones Sociales y sus Relaciones con la Construcción del Conocimiento en las Artes Visuales cuando decidí hacer este máster en la Universidad de Barcelona así que, teniendo en cuenta las lecturas realizadas en el ámbito de los Estudios de la Cultura Visual y del Imaginario desde las Representaciones Sociales, he puesto gran interés en poner el cine en estas relaciones y pensar cómo se podría conectarlo a las perspectivas educativas contemporáneas. Sobretodo, lo que más me llamaba la atención y despertaba el interés era estudiar las relaciones que se establecen entre los papeles del alumnado y el profesorado (teniendo en cuenta mi experiencia como profesor de Educación Artística desde hace 6 años en una escuela privada en Brasil con niños, adolescentes y jóvenes) y 
pensar alternativas que podrían favorecer una aproximación entre estos dos grupos (no solo en el campo del arte) dónde las decisiones podrían ser tomadas entre todos y todas y donde lo vivido pudiera formar parte de lo académico.

La oportunidad de participar de un Proyecto de Trabajo con Fernando Hernández en el Curso de Historia y Currículum de la Educación Artística de la Universidad de Barcelona (BBAA) me abrieron ventanas a mi tema de investigación: el Cine como punto de partida para aprender desde nosotros y nosotras mismos qué relaciones se podrían crear a partir de esta aproximación desde Proyectos de Indagación.

En el proyecto inicial estaba Fernando Hernández en la posición del profesor titular de la signatura y después otras perspectivas de estudios se fueron añadiendo con la entrada de Noemí Durán y Michelle Dezember y yo mismo en el proyecto.

A continuación empezamos nuestro proyecto de investigación con todo el grupo, a partir de la película "La Clase" (Entre les Murs, Laurent Cantet, Francia, 2008) con el deseo de descubrir todo lo que se podría aprender desde ella a partir del desarrollo de Proyectos de Trabajo y de Investigación. Desde allí, nosotros cuatro, que hemos compartido con las demás estudiantes cuales eran nuestros intereses en el curso, pasamos a estudiar juntos con ellas (el grupo lo formaban mujeres) lo que cada una podría añadir desde sus propias lecturas e investigaciones.

Así que, en el proyecto que fue desarrollado en la signatura a lo largo de los meses de febrero hasta junio se construyeron a partir de las redes que todas hubieron tejido (como la concepción "rizomática" de Deleuze acerca de la construcción del conocimiento), visibilizados en este proceso de manera muy colaborativa donde las ideas fueron añadiéndose de acuerdo con los intereses que se las despertaron a lo largo del tiempo compartido. Pues, todas las personas implicadas en el proyecto buscaron acercarse a campos de estudios contemporáneos, donde partiendo de sus planteamientos iniciales los convirtieron en nuevos planteamientos más complejos relacionados a problemáticas educacionales y sus posibles repercusiones en una nueva narrativa sobre la educación. Bajo estas ideas, la concepción del rizoma como una forma de pensar la construcción del conocimiento, la conectividad entre los distintos conceptos que requieren una multidisciplinariedad (como defienden los Estudios de Cultura Visual), en este caso, las narrativas donde cada una se ponía en relación al entorno, desde sus propios relatos y las distintas voces y matices que fueron añadidos, el camino recogido que ahora comparto, creo, muestra un proceso de actividad intensa y de gran importancia no solo para mí, sino principalmente para todas quienes participaron. 
Desde allí, lo que planteamos en nuestros primeros encuentros del "grupo proponente" (formado por Fernando, Michelle, Noemí e yo) fue pensar en una propuesta que pudiera contemplar los Estudios de la Cultura Visual desde el Enfoque Construccionista en el Curso de Historia y Currículo, presentado por Fernando y que ya tenía un histórico de proponer maneras distintas o "performáticas" de construir la signatura.

Cuando durante el pasado verano de 2008 comencé a pensar en el curso de Historia y Currículum de Educación Artística tenía presente las dos experiencias anteriores en las que habíamos intentado construir una aventura de aprendizaje en colaboración. Una aventura planteada desde una organización basada en lo que los estudiantes querían aprender (de abrir-se a su deseo de aprender), y que nos permitiera construir una historia de la educación de las artes (de la educación en general) desde una disposición para la indagación en torno a nosotros mismos y lo que nos preocupa e inquieta de lo que nos parece que sucede 'ahí fuera. (Fernando Hernández. Documento de autoevaluación del curso)

Así que, a mediados de enero (el curso se llevó a cabo entre febrero y junio de 2009) empezamos a intercambiar ideas, mails, textos, lecturas y a construir un "guión" inicial de lo que haríamos en las primeras clases. De esta manera, la primera propuesta fue empezar las discusiones sobre el profesorado y la relación pedagógica a partir de una película francesa que acababan de estrenar en los cines españoles.

Esto fue lo que tuvimos en cuenta en la primera reunión del grupo: vamos a ver "lo que nos dice desde nosotros esta película y lo que podremos aprender de ella". Y después de la sesión del cine, creo que buscando las cosas que tendríamos en nuestra "mochila" (como nos diría Fernando), nuestro guión había pasado a definirse un poco más: Michelle con la Historia Crítica, Noemí con la Perspectiva Narrativa, Fernando sobre los Proyectos de Trabajo y yo con las relaciones entre Cine y Educación y los Proyectos de Indagación.

En las sesiones que siguieron, poco a poco los debates fueron definiendo cómo podría ser el curso. Y lo que decidimos en el grupo fue que primeramente nosotros (los proponentes) empezaríamos presentando el primer proyecto entorno a la película "Entre les Murs" y que después, sucesivamente, cada grupo escogería una película con temática relativa a la representación del profesor, el alumnado, la relación pedagógica, la Escuela y haría una investigación entorno a ella y nos las presentaría. Decidimos también que los debates y discusiones iniciados en las clases tendrían continuidad en el espacio del Campus Virtual de la UB donde la gente podría poner allí sus percepciones o cosas que les gustarían añadir. 

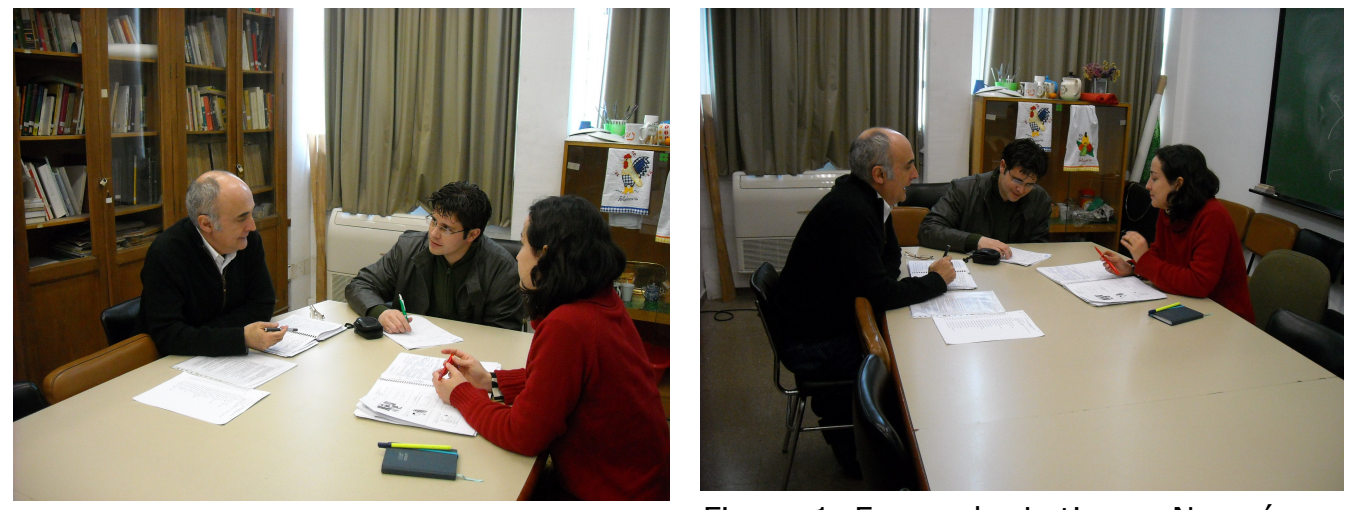

Figura.1. Fernando, Lutiere y Noemí cambiando ideas sobre el curso (enero de 2009).

Los textos y las críticas sobre la película en cuestión y todas las informaciones que hubiéramos conseguido añadir en estos encuentros nos servirían para presentar a las estudiantes nuestros planteamientos iniciales e incluir sus sugerencias y aportaciones. La educación por proyectos y temas de investigación como una proposición 'construccionista' por parte de Fernando nos abría la oportunidad de empezar las discusiones cuestionando las narrativas puestas en diálogo con intensiones y tensiones, deseos, experiencias y lo que Eisner denomina como 'modos de ver y acercarse de la cuestión', o sea, se nos invitaba a examinar nuestras experiencias, revisitar lo que teníamos nosotros en "nuestra mochila" y a poner "las cartas sobre la mesa" y desde allí empezar a construir una nueva narrativa donde los cuestionamientos particulares podrían cobrar un sentido.

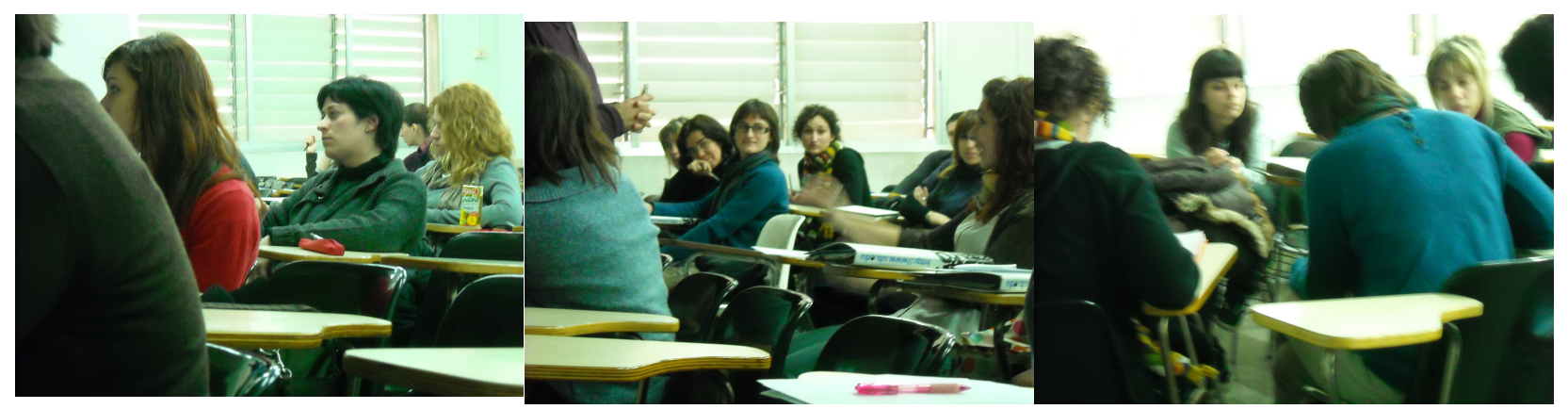

Figura 2. Visión de parte del grupo en el aula en las primeras sesiones (febrero de 2009).

Además de contar parte del proceso que hemos desarrollado a lo largo del curso, mi intento en esta exploración es principalmente reflejar como tiene lugar la investigación en el campo de la educación de las artes visuales, el intercambio de conocimientos que parte de proyectos de indagación y la experiencia de aprender desde los relatos personales y compartidos desde una perspectiva construccionista. 
Sin embargo, debido a la complejidad, amplitud e intensidad de lo vivido y experimentado a lo largo del tiempo compartido, y también por tener en cuenta cual es el objetivo principal de este relato, estoy seguro de que es imposible narrar todo lo que fue desarrollado, lo qué o cómo ha afectado a cada uno, las aportaciones personales, y por lo tanto, al contar un poco lo que ha pasado, mi intensión es solo situar de dónde hemos partido y por dónde hemos transitado.

A medida que el proceso se desarrollaba empecé a reflejar y reflexionar sobre cómo estaban siendo construidas las relaciones entre las estudiantes implicadas en un Proyecto de Trabajo y un Aprendizaje Colaborativo. Desde ahí fui construyendo mi perspectiva de estudio situando marcos conceptuales amplios, dentro de los cuales mi tema de interés podría cobrar un sentido concreto. En este sentido, la formulación de preguntas iniciales fue igualmente importante. Si antes sólo tenía en la mente la cuestión de la subjetividad producida por el cine, ahora había introducido la cuestión del aprendizaje colaborativo, del conocimiento compartido, de los proyectos de indagación, de lo espacio virtual y las relaciones con los Estudios de la Cultura Visual. Todo ello me abrió nuevas puertas a planteamientos más cercanos de lo que estaba viviendo.

Sin embargo, creo que cada una de las preguntas que me pasaban exigía una gama muy larga de entrelazamientos, de investigación, que no podría ser contemplada en solo este trabajo y que me haría decidirme por una cuestión principal: ¿qué significa aprender desde Proyectos de Indagación?

O sea, pensar qué me ha aportado esta experiencia de aprender a partir de cuando uno se pone en evidencia y cuando parte de sus propios relatos y cuestionamientos para desarrollar proyectos de indagación. Esto ha pasado muy claramente en el curso que he acompañado y no solo con el grupo, sino que yo me incluyo también en este proceso. A partir de ahí, los proyectos desarrollados por los cuatro grupos de trabajo formado por las estudiantes del curso, me ofrecen elementos, datos, asimismo como mi propio proceso de construcción de la experiencia de aprender, para intentar a partir de esta pregunta construir una narrativa que en mi opinión pueda ser pensada como una experiencia de aprendizaje alternativa a la educación contemporánea.

\section{Por dónde sitúo...}

Una de las características de las perspectivas contemporáneas de la educación de las Artes Visuales adoptadas en esta investigación es su deseo de proponer miradas más críticas, personales y que posibiliten la apertura a una gran variedad de prácticas culturales, acciones y experiencias estéticas y/o visuales, de reflexión y de construcción 
de conocimientos a partir de aquellas manifestaciones estéticas que transcienden lo tradicional. Acompañando este ideario, el enfoque epistemológico y metodológico acogido en esta investigación pretende traer a la discusión algunas ideas del campo de estudios de las pedagogías culturales contemporáneas que estén relacionadas a la construcción del conocimiento.

En este sentido, los Proyectos de Indagación construidos por las estudiantes se nos ofrecen datos para visibilizar y reflejar lo que tenían en cuenta como preguntas personales y principalmente sobre cuestiones acerca de la escuela, su funcionamiento, las cuestiones del orden, disciplinamiento y otros temas que se generan en este contexto a partir de sus Proyectos de Trabajo. Asimismo, teniendo en cuenta también que el "guión" del curso que era construido de manera compartida y desde múltiples miradas, la conectividad con el enfoque Construccionista que parte de lo relacional, de lo que se construye como rizoma a partir de lo local y social, creo que mucho de lo que proponen estas perspectivas pudieron ser igualmente visibilizados en las "entrelíneas" de lo que ha pasado.

Con la intención de responder a las necesidades de acercarse de las "prácticas de la visión" y el abanico de representaciones que desde ahí se establecen desde la perspectiva de la cultura creo que tener en cuenta los Estudios de la Cultura Visual nos favorece una amplitud de disciplinas y concepciones que nos ayudan a pensar de manera más consciente y crítica sobre la intencionalidad de estas imágenes. Pensar lo que estas imágenes dicen "de mí", "desde mí" y como me veo y me percibo a través de ellas son también estrategias utilizadas por estas visiones de la educación actual que nos han movido a partir del cine como un eje inicial.

El cine como punto para pensar las concepciones, roles y papeles sociales del profesorado, del alumnado, de la escuela y sus sistemas de organización y de reglamentación, las imágenes presentadas, sus representaciones y sus efectos en la vida cotidiana desde la Perspectiva Construccionista de los Estudios de la Cultura Visual adoptada supone una visión multidisciplinar y amplia a todo lo recogido durante el desarrollo del proceso. Partiendo de distintos campos sociológicos y culturales que contribuyen para favorecer una mirada amplia de las experiencias visuales cotidianas, creo que se justifica la aportación a los Estudios de la Cultura Visual una vez que esta noción hibrida del conocimiento que se construye desde la mirada fue también parte de este proceso al acercarse del cine en primer instancia. 
En esto sentido, el Concepto Construccionista defendido por Kenneth Gergen que parte desde relaciones cada vez más dialógicas, desde distintos puntos de vista (de acuerdo con cada cultura y contexto) creando nuevas formas de entendimiento donde la concepción de la realidad se sitúa en el proceso de relaciones que también parte de otra trama de relaciones, creo se conecta a los proyectos desarrollados por los cuatro grupos de mujeres investigadoras. Lo que pude percibir a partir de lo que hubieron compartir en el espacio virtual fue un mosaico de fundamentaciones, perspectivas, experiencias de vida, relatos personales además de informaciones sobre el funcionamiento del curso.

Al problematizar las comprensiones más cotidianas, los hechos y experiencias que normalmente son tratados como algo fijo, institucionalizado y dentro de la llamada "normalidad", lo que se percibió en estos Proyectos de Indagación fueron perspectivas de trabajo que no siguen la lógica académica que casi siempre propone investigar "desde fuera", dado que aquí se pudo ver lo que se construye "desde dentro", o sea, que tiene como punto de partida uno mismo. O sea, pensar los Proyectos de Indagación desde lo que significa, ponerse en el centro de la cuestión, pensarse a partir de lo que afecta al entorno, desde las dudas, desde lo que puede tener distintos significados y desde lo que se construye desde la propia experiencia de aprender.

El conocimiento desde este enfoque no tiene una única forma de entender el mundo pero parte de una variedad de disciplinas, o sea hace con que las múltiples miradas puedan ser contempladas. También propone cuestionar lo que está puesto y a cultivar el sentimiento de transgresión, de cambio y de dar cuenta de una experiencia. En este sentido, para Kenneth Gergen "cada uno trae consigo mundos de posibilidades y (...) pensar que estas relaciones nos otorgan alas (...) cada ves que relacionamos ampliamos nuestras posibilidades de volar" (Conferencia en la Escuela de Psicología Adolfo Ibàñez, 22 de septiembre de 2008/ en la web en 22 de julio de 2009) me hace pensar que experiencias como esta pueden servir para el desarrollo de un aprendizaje más colaborativo, de toma de consciencia y responsabilidad social que responda a las necesidades actuales.

En este sentido, creo que esta manera distinta de proponer una investigación científica pueda también estar de acuerdo con lo que se nos presenta a partir de lo que sería una Investigación educativa Basada en las Artes, donde el método y las relaciones con la construcción de los conocimientos siguen una perspectiva más maleable, performática y singular. Una perspectiva metodológica que se nutre en parte de sus propias experiencias y relatos personales para poder desarrollar un proceso investigador. 
El desafío de la IBA es poder ver las experiencias y los fenómenos a los que dirige su atención desde otros puntos de vista y plantearnos cuestiones que otras maneras de hacer investigación no nos plantean. En cierta forma, lo que pretende la IBA es sugerir más preguntas que ofrecer respuestas. (HERNÁNDEZ, 2008: pág. 94)

Así que, en el contexto de esta investigación, pensar las conexiones desde el acercamiento a la cultura, desde su dimensión social, política y pedagógica a los planteamientos de una Investigación Educativa Basada en las Artes me parece un buen comienzo para poder tornar visible lo que podría aparecer fuera de la mirada, o para escuchar las voces que normalmente no se escuchan. Igualmente reflexionar sobre la gente y sus representaciones y las derivaciones que tienen desde sus aspectos sociales, de género, sexo, clase, raza y todo lo demás que abarca el abanico de la cultura que se presenta desde el cine, sirvieron para pensar también qué modelos de hombre y de mujer, y en este contexto específicamente del profesorado, que se construyen a partir de estas narrativas y a partir de ahí esbozar algunas ideas.

\section{El cine para Desaprender y Reaprender}

Desaprender é algo mais que aprender coisas opostas sobre um mesmo tema, assunto, valor, questão da vida. Desaprender pode até indicar, erradamente, a idéia de esquecer o aprendido. Porém, o seu significado e intenção é exatamente o contrário. [...] Desaprender é aprender a não querê-las mais para si; a não outorgar mais o estatuto de verdade, de sentido ou de interesse. Verdade aprendida com outros, desde sempre, adquire valor de inquestionável. Desaprender é animar-se a questionar tais verdades. Desaprender é, também, fazer o esforço de conscientizar todo o vivido na contramão, evocando o impacto histórico e emocional que teve aquela aprendizagem que hoje deseja ser modificada (FRESQUET, 2007, p. 49).

El concepto de desaprender para aprender cosas nuevas o mismo "reaprenderlas" desde otro punto de vista propuesto por Adriana Fresquet en "Imagens do Desaprender" también puede conectarse a lo que ha pasado en este curso. Al final del proceso, después de todo lo vivido (si puedo decir que ha sido intenso, afectivo y de grande colaboración) y tomando como base las narrativas puestas en el espacio virtual, las autoevaluaciones de las personas participantes, más allá de una simple tarea creo que no sólo han visto desde distintas maneras (así como yo) el proceso que envuelve el aprender sino también investigaron desde otras miradas, desde otras lógicas lo 
aprendido desde siempre ( $y$ desde la escuela que han frecuentado) poniéndose ellas mismas en relación a lo que pasaba en su entorno. Desde sus propias indagaciones o dudas, el camino por dónde han marchado se conecta con la idea de Fresquet sobre el desaprender para aprender desde distintas maneras y conexiones. El fragmento del relato de Carmen, una de las estudiantes del curso, se nos presenta como una mirada que parte desde una resignificación de conceptos, y donde pone la cuestión de lo afectivo, desde el interés particular conectado a lo relacional en el ámbito del aprendizaje:

\begin{abstract}
Este proceso relacional (con las compañeras, con los docentes, con la bibliografía, con las películas, con la música) me ha llevado a repensar mis narrativas respecto a muchos conceptos tratados en clase. Como diría Paula a "rumiar" o como diría Carla Padró a "anar teixint i desteixint", a aprender y desaprender. A cuestionar. Me ha encantado leer, entre otras cosas, algo de Foucault, Deleuze y Pennac. Ha sido "para mí" y eso me gusta. Sabía que casi no podría reflejarlo en el proyecto, pero lo he disfrutado igual. Me han descubierto un territorio apasionante, me han ayudado a abrir nuevos interrogantes, a no poner "punto final". He aprendido a trabajar en grupo sin tratar de dirigir ni de que me dirijan. He hecho pocos trabajos grupales $y$, al igual que a $\mathrm{Ma}^{\mathrm{a}}$ del Mar, me daba un poco de miedo. (Carmen. Documento de autoevaluación del curso)
\end{abstract}

De esta manera, partiendo desde la idea de plantear una planificación del curso donde los contenidos o temas referentes a las cuestiones educativas del ámbito escolar pudieran estar conectados a las aportaciones personales del grupo es que se optó por empezar por una película en que su contexto fílmico estuviera relacionado con el tema de la Escuela, de lo que el director 'representa' de una clase de secundaria. Así que el cine hubiera ser el punto dónde he(mos) comenzado a cuestionar(se) y a pensar qué es el aprender y cuáles son las aportaciones que cada una puede lograr desde allí a partir de sus propias indagaciones.

\title{
"Entre les Murs" como un punto de partida
}

Fue a partir de "Entre les Murs" que preguntas sobre el universo educativo y relaciones entre los sistemas de reglamentación, disciplinamiento, el terreno afectivo y el aprendizaje se hicieron presentes, tomaron forma y se convirtieron en Proyectos de Indagación. Igualmente a Giroux (2003, p. 28) cuándo habla del cine como importante vehículo de ideologías y visiones del mundo y de la cultura, también con este sentido creo fue introducido el filme en este proceso de aprendizaje.

Cuando era un joven espectador de cine en Providence, Rhode Island, creía que las películas sólo ofrecían la diversión del entretenimiento. No tenía ni idea de que desempeñaban también 
un papel activo en la conformación de mi sentido de la vida cotidiana, ofreciéndome una educación moral y política que en su mayor parte pasaba desapercibida y quedaba sin réplica. Las películas me han reportado muy buenos ratos a lo largo de toda mi vida, pero también me han capacitado para plantearme más críticamente (el placer adquirido del análisis) [...] Todas las películas transmiten ideologías y apelan, a veces de un modo claro, otras contradictoriamente, a visiones del futuro, estimulan o estupidizan diversas maneras de estar en el mundo. (GIROUX, 2003, p. 28)

Así que, partiendo de una película que se centra en la figura del profesor en el aula pasamos a desarrollar un proyecto de aprendizaje en un curso de formación del profesorado que ha posibilitado no sólo contemplar o analizar la sucesión de imágenes, sino también ofrecer la oportunidad de exponerse al cine, dejarse llevar por la narrativa, ponerse en relación con lo que decía la trama y pensar sobre los efectos que tendría en cada una, lo que pudiéramos aprender de nosotros mismos en estas representaciones puestas en la pantalla.

El espacio donde ocurre la trama de "La Clase" (título en español de la película "Entre les Murs", de Laurent Cantet, Francia, 2008) se nos representa otros tantos muros de muchas otras escuelas, algunos alumnos de origen multicultural, profesores en una lucha desenfrenada contra las dificultades del sistema educativo, lo que parece una de las realidades de la educación no solo en Francia sino en diferentes partes del mundo. Con una estética documental, desde los primeros minutos hasta completar sus casi dos horas de duración, la película muestra alumnos actores y profesor también actor presentando frente a la cámara parte de sus vidas en un instituto, sus dilemas, sus angustias, sus deseos y creencias y principalmente el choque entre generaciones, culturas, y principalmente la ineficiencia del sistema educativo.

Tomando como referencia el libro de Françoise Bégaudeau, el profesor de lengua que escribió sobre su experiencia dentro de una clase de un instituto multicultural de París, la película no sólo representa un espacio de mezclas desiguales, sino también un espacio lleno de muchas voces, de un espacio-tiempo lleno de extrañamientos, de emociones y sensibilidad y consecuentemente de conflictos. Conflictos que empiezan por embates entre palabras, entre puntos de vista distintos y lejanos que muestran las dificultades de dialogar con la diversidad en un mundo cada vez más cambiante y distinto.

La película como herramienta o reflejo de un determinado rasgo de una problemática actual a la luz de las Perspectivas de la Investigación recogidas en este trabajo fueron puntos de gran importancia a la planificación del curso. Fue a partir de los planteamientos iniciales proyectados a partir de la película que las preguntas se 
convirtieron en Investigaciones y cobraron sentido. Luego, el proceso construido por cada uno de los grupos de mujeres muestra también un recogido de autores, contenidos e ideas que revelan sus modos de articular los conceptos y dónde se posicionan en estas relaciones.

\section{De los Proyectos de Trabajo a los Proyectos de Indagación}

Los Proyectos de Trabajo defendidos por Fernando Hernández $(1998,2000)$ dónde el guión a la aprendizaje parte de una planificación dónde el profesor no es el único que decide lo que el grupo va a aprender, pero desde una relación dialógica en qué todos y todas son invitados a definir los caminos y metodologías que si seguirán es igualmente lo que ha pasado en este curso. Sin embargo, más allá de una planificación metodológica, en este caso, la indagación fue el eje central de los Proyectos de Trabajo.

Para empezar las discusiones después de la película, como un punto de referencia Fernando preguntaba a todos los grupos: "Amb què penses que connecta aquesta pel.lícula amb la teva actual situació? Quina realitat construeix la narrativa del film? Quines preguntes et planteja la pel.lícula en relació amb les històries que ens mostra?"

A partir de allí se formaron cuatro grupos para hablar y cuestionar temas que tenían que ver con sus propias vivencias y relaciones contextuales, donde el film les servía como un punto desde donde empezar la discusión.

Fernando nos ha pasado un power point que mostraba el esquema de trabajo, que habían preparado Michelle, Noemi, Lutiere y él mismo, para trabajar el proyecto acerca de la película La clase. Era su programación, la "mochila" que el docente lleva al iniciar un proyecto, pero que habitualmente no muestra al los alumnos. [...] Nos ha pedido, después de agruparnos en grupos pequeños, que trabajáramos con las preguntas que aparecían en el power point, pero no sabíamos bien cómo hacerlo. Se han dicho cosas como 'no tenim gaire clar res', 'hem d'anar step by step, és massa dens', 'hauriem de començar a veure pel-lícules abans de saber per quin camí tirar'. (Diario de la Clase, relato de la sesión hecho por Carmen, 23/ 02/ 2009).

Desde aquí, las conversaciones de los grupos a partir del visionado en la película, surgieron los cuatro ejes relacionados con el contexto educativo que iban a servir como tema de investigación de cada uno de los grupos: el respeto, la invisibilidad, la disciplina y el conflicto. 
El primer grupo que hablaba del 'respeto' a partir de "Entre les Murs" planteó como preguntas iniciales: "Què és el respecte? Com l'interpretem cada una de nosaltres? Sempre basant-nos en una experiència personal, tant com a alumnes, o com a educadores... Rol del professor i dels alumnes en relació al respecte. Com es posiciona cada un d'elles davant d'aquest terme? Podem parlar així de límits?"

El segundo grupo que buscaba indagar sobre la cuestión de la invisibilidad de algunos alumnos partió de la necesidad de pensar sobre la 'invisibilidad, la ocultación, el silencio, la discreción, la exclusión, la estrategia, el disimulo y el silenciamiento'.

El tercer grupo trajo como puntos de interés para cuestionar las siguientes preguntas: "¿Qué es la disciplina? ¿Qué modelos de disciplina nos muestran la película? ¿Cómo los medios de comunicación influyen en nuestra manera de entender la disciplina? ¿Por qué en la actualidad tenemos que retomar la cuestión del sistema disciplinar? ¿La disciplina ayuda a aprender? ¿Ayuda a enseñar?"

Por fin, el último grupo se planteó acercarse al 'conflicto' como eje principal, y se preguntaron: "¿Qué se entiende por conflicto? ¿Qué tipo de conflictos son más habituales en las clases? ¿Cómo son vistos estos conflictos?"

Como se pudo percibir, estas preguntas iniciales que se despertaron a partir de la película y que son también cuestiones que tienen que ver con las propias historias personales, pueden ofrecernos una posibilidad para pensar las relaciones que se establecen a la hora de construir un guión o un punto de partida desde dónde comenzar una investigación.

Después de la delimitación de las temáticas, en las sesiones siguientes cada uno de los grupos hizo una presentación de lo que había dialogado o conectado, partiendo siempre desde sus propias experiencias. Sin embargo, además de los dos encuentros semanales de sólo cuatro horas en la Universidad, fue en el Espacio del Campus Virtual del Curso donde los debates continuaron, donde empezaron a intercambiar ideas no sólo sobre los temas de los trabajos, sino también en torno a otros puntos de interés que fueron apareciendo en el camino.

La forma como los grupos se organizaron desde la planificación de los temas que les gustarían investigar alrededor del tema principal (el respeto, la invisibilidad, la disciplina y el conflicto) muestra que cada grupo ha utilizado una lógica que parte de cuestionamientos iniciales a la complejidad de una investigación académica. Después de 
elegido el tema central de la encuesta, se han dedicado a una búsqueda de autores, conceptos y teorías que tratan del tema seleccionado. Entonces, haciendo cruces entre lo personal y lo que habían recogido a partir de los datos que tenían, reconstruyeron una narrativa que pudiera dar cuenta de la pregunta que buscaban contestar.

En este sentido, los aspectos referentes a qué tipo de subjetividad docente se construye y se presenta a través del cine, cómo se perciben a través de las representaciones sociales construidas en el cine, qué aprenden de sí mismas y a partir de las imágenes que se les presentan, y principalmente, dónde han llegado con sus entrelazamientos entre los relatos personales y los cuatro temas de interés con las perspectivas de estudio que habían escogido, al fin y al cabo escenifican una experiencia de aprendizaje colaborativa y significativa.

A partir de historias personales en distintos contextos y papeles, empezaron a trazar puentes, tramas y relaciones entre el poder, la política, la subjetividad y el género y sus efectos en la construcción de las realidades en que viven. Utilizando incluso del ideario de Foucault (aún que en general de manera no explícita) mostraron que es posible inserir nuestros propios relatos en el contexto académico y que estas producciones basadas en lo personal y lo artístico nos ofrecen seguramente una gran cantidad de elementos para establecernos lógicas distintas, performáticas, personales y críticas de ver que son más acordes con nuestra contemporaneidad.

El paso siguiente que dio el grupo, en la dirección de apropiarse de la perspectiva de los Proyectos de Trabajo (Fernando Hernández, 1998, 2000) demuestra que lo recogido en la primera parte, en la indagación en torno a la película 'La clase', ha permeabilizado su saber, y se refleja en mucho trabajo y dedicación que mostraron y en la cantidad de textos, links, materiales relacionados que se debatía en los foros y que las estudiantes iban añadiendo en el Campus virtual. Esto demuestra que cuando lo que se aprende tiene un sentido, una aproximación a lo personal, a lo vivido y a la experiencia el placer por aprender se transforma en motivación que lleva a dedicarse a ampliar lo que se aprende.

En este sentido, es importante destacar que el espacio en el Campus Virtual ha ido más allá del simple lugar donde se ponen comentarios o materiales de lectura; ha sido una importante herramienta de diálogo, de continuidad de los debates, de intercambio de ideas y otra alternativa a la construcción de conocimientos. A lo largo del desarrollo del 
proyecto las reflexiones que empezaban en las clases tuvieron continuidad en los foros, debates y discusiones y muchos otros temas pudieron ser 'transversalizados' desde allí.

Lo que también me ha llamado la atención fue el sentimiento de colaboración presente en el grupo: las estudiantes ponían en el Campus Virtual además de sus comentarios acerca de la película materiales de apoyo, links, otras películas, o sea, todo lo que iban encontrado en la web y que podría ser de interés para las demás compañeras. Igualmente este sentimiento de aprendizaje colaborativo pudo ser percibido en las autoevaluaciones finales donde el punto clave en que prácticamente todas las estudiantes han coincidido estuvo relacionado con la experiencia del grupo, con las aportaciones que el grupo construyó con las demás y de manera compartida.

Poniendo en cuestión los sistemas educativos vigentes estas "espigadoras de la Cultura Visual" (HERNÁNDEZ, 2007) propusieron a partir de lo que colocaron "en la mesa", que otras formas de pensar la escuela, las jerarquías, las relaciones personales y de poder, los problemas de regulación y de indisciplina, que otras maneras de favorecer el aprendizaje se podrían lograr mediante una educación de las artes más amplia y democrática, y a la vez, más personal.

De misma manera, a partir de lo que hicieron, puedo decir que realmente es posible crear situaciones que favorezcan un aprendizaje compartido y donde uno enseña y aprende al mismo tiempo que comparte sus propias experiencias de vida y conocimientos a partir de colocarse también en relación a lo que se habla. Incluso el maestro que normalmente se proyecta como el eje central de un aprendizaje, en este caso, es lo contrario: el maestro es más uno del grupo y está allí para hacerse de intermediario e igualmente es alguien que también aprende. $Y$ desde allí, el conocimiento gana un sentido más significativo, un valor personal que parte de "dentro para afuera", o sea, desde lo que cada una aporta y que puede ser útil para las demás en medio al proceso de aprendizaje.

A partir de eso, creo que los cuatro Proyectos de Indagación desarrollados por ellas deben en gran parte al Campus virtual el mérito de haber ofrecido la posibilidad de "diálogo" casi diariamente, pues durante los cinco meses que han dedicado a la asignatura de Historia y Currículo de la Educación Artística ha facilitado los debates y la organización del grupo. 
Los cuatro ejes finales de investigación que escogieron las estudiantes partieron desde las cuatro películas que seleccionaron como punto de partida para el desarrollo de sus proyectos:

El primer grupo se puso a pensar sobre el deseo de aprender desde la película "Buda va explotar de Vergonya". El segundo grupo quiso reflexionar sobre los límites y las relaciones entre el profesorado y el alumnado y la confusión de los sentimientos a partir de la película "Half Nelson". El tercer grupo partía de la película la "Sonrisa de la Monalisa" para hablar del conflicto y la trasgresión. Y por último, el cuarto grupo quiso investigar sobre la experiencia de aprender a partir de la película "Diarios de la Calle".

En estos cuatro proyectos de investigación se han utilizado desde distintas miradas hasta distintas metodologías, formas de acercarse a la cuestión de la indagación, autores teóricos, perspectivas y conceptos puestos en conexión con lo que cada una trajera como historia personal al contexto pedagógico. Además, se tuvieron en cuenta películas en que el profesor o la profesora fuera el eje central de la dramatización, o en el caso de la película escogida por el primer grupo que cuenta la historia de la niña que se pone en lucha contra el sistema cultural y social en el que vive para poder realizar el deseo de aprender. En los cuatro proyectos se queda evidente el deseo de cambiar los sistemas vigentes desde las estructuras materiales y sociales existentes para promover otras maneras de plantear la educación actual.

Desde aquí, las vinculaciones entre los deseos del aprender y los caminos para la trasgresión, de apertura a nuevas ideas y concepciones de la escuela actual se convirtieron en el eje central de las discusiones. Todo ello sin perder de vista las historias particulares de cada estudiante. También la cuestión metodológica, es decir, la manera de recoger cómo se ha transitado (a partir de un diario de clase que cada semana realizaba una persona), por dónde se han movido, cuáles han sido las referencias que se han utilizado, qué perspectivas apuntan y lo que hacen durante la búsqueda se nos presentan a su vez, como temas de indagación.

El deseo de aprender desde las concepciones actuales del conocimiento a que han hecho búsqueda a algunos teóricos como Gilles Deleuze, también muestran que la metodología fue la misma de la tarea anterior: se han hecho un guión inicial de preguntas que les gustarían contestar y que estuviesen conectadas al tema de la signatura (Historia y Curriculum de la Educación) y del proyecto inicial al entorno de "Entre les Murs". También se han puesto a dialogar con los conceptos que desde ahí surgieron dónde el grupo proponía una nueva mirada del deseo desde perspectivas educativas que podrían 
contemplar estas ideas para lograr una educación más consciente de lo que esperan las estudiantes en las escuelas. Así que, el grupo uno se ubicaba a examinar el ideario cultural y social que abarca qué es el deseo y qué efectos tendría en la cultura escolar y su relación con el concepto de aprender desde el disciplinamiento y esfuerzo y no por el deseo personal.

Mirian Grau, una de las mujeres del grupo uno hacía un recogido a las ideas del artista Judith Barry para hablar de la importancia y necesidad del deseo en un proceso de aprendizaje y también a la investigación:

Me gusta investigar y considero el hecho de hacer arte como una oportunidad de estudiar detenidamente ciertas cuestiones. ¿Qué está ocurriendo en el mundo que me está afectando personalmente a mí? ¿Cómo estoy procesándolo y cómo puedo reflejarlo? En mi caso, normalmente, el resultado final no es solo una obra plástica, sino también un artículo o un libro. (Miriam Grau, 2009, reflexió 1)

El tema del deseo de aprender investigado por el grupo uno sobre la óptica de Deleuze se conecta a las reflexiones hechas por el grupo cuatro que tenía en cuenta explorar la experiencia de aprender a partir de la película "Diarios de la Calle" en qué el contexto conflictivo (entre alumnos y profesores) también reflete la necesidad de conectar el aprendizaje a lo que es significativo al contexto social (que parte del deseo) para producir miradas críticas.

Relacionado a las ideas y creencias, prejuicios, estereotipos y miradas "eurocéntricas" del proceso que envuelve el aprender y la posibilidad de construir otra perspectiva a este entorno es que se han guiado el grupo cuatro en su Proyecto de Indagación. El conflicto escenificado en la pantalla por la maestra que se dedica a entender el contexto social y se empeña en despertar el gusto por el aprender en sus alumnos en un instituto a partir de la utilización de elementos que son referencias para ellos, como también la cuestión de la motivación del profesorado cuándo el contexto material no favorece las relaciones personales, e incluso la idea del embate que se puede generar en estas relaciones conflictivas fueron discusiones y preguntas a que este grupo se puso a debatir. Igualmente que los otros tres grupos, el proceso desarrollado también hubiera partir de indagaciones para desarrollar un recogido de aportaciones que pudiera construir una nueva narrativa de la cuestión.

El tema afectivo y pertinente al sentimiento y el conflicto que se puede generar en estas relaciones personales entre el alumnado y el profesorado que fue el eje por dónde se han 
movido las mujeres del grupo dos se nos presenta un recogido de ideas y relaciones dónde buscaron situar las preocupaciones sobre la reciprocidad de los sentimientos y su influencia en el aprendizaje. A partir de un repaso de muchas preguntas (empezando por los elementos visuales presentados en la película y sus posibles significados) semejante a los otros tres grupos lo que han hecho fue buscar contestar las múltiples preguntas que hubieron plantear sobre estos límites y reflexionar sobre los distintos papeles en este contexto relacional.

Partiendo de la idea de ir más allá de lo convencional que propone otras miradas y que pueda romper con la normalidad aceptada es que se ha planteado el grupo tres que partiera de la narrativa fílmica que cerca el personaje de Julia Roberts en la película "La Sonrisa de la Mona lisa". El sentimiento de transgresión y el deseo de cambiar a los sistemas actuales de educación son aspectos que se conectan a las discusiones llevadas al cabo por este grupo.

\section{Al fin y al cabo, ¿qué significa aprender a partir de los Proyectos de Indagación?}

"Durante días he estado pensando en qué es el deseo, en qué es aprender, en qué es un proyecto de trabajo, pero de una manera tan aséptica, tan higiénica y tan alejada de la realidad de la película que sentía que me dejaba algo importante

y... vaya si lo dejaba. No por obvio, no por conocido, se puede ignorar la realidad de donde nace esta historia bonita a veces, pero terrible y rayana en algunos pasajes a una historia de terror. No creo que se pueda actuar como un cirujano que tapa el cuerpo del paciente para concentrarse sólo en el órgano que desea operar, pero eso es precisamente lo que estaba haciendo".

(Carmen. Documento de autoevaluación del curso)

Conectada a cuestiones que tienen que ver con prácticas que parten de la experiencia frente a la pantalla del cine, donde lo afectivo y la subjetividad tienen gran importancia es igualmente de gran valor la necesidad de pensar estas imágenes y las narrativas que desde ellas se construyen para producir formas más críticas y políticas de ver. Creo que es a partir de proyectos como lo que aquí hablamos que podremos lograr una formación más de acuerdo con lo que nos pide la educación de nuestro tiempo donde el cine (tan presente en el cotidiano) puede desempeñar importante función en estos procesos de enseñar y aprender y quizás más que esto, despertar preguntas para pensar el propio mundo y sus modos de ver.

Todos los discursos producidos a partir del debate al entorno a la película Entre les Murs resaltan las diferentes perspectivas que pueden surgir y los innúmeros planteamientos 
que se pueden construir desde estas relaciones, incluso el impacto visual de la narrativa cinematográfica y sus relaciones con la propia vida a partir de los Proyectos de Indagación que han sido producidos por las estudiantes. Creo que todos los relatos que han generado a este entorno muestran maneras de percibir el cine no solo como una ilustración, pero principalmente como una posibilidad de mejor desaprender y reaprender a las cosas desde una mirada crítica y reflexiva.

Me parece que desde aquí es muy difícil pensar en la educación de las Artes Visuales hoy sin tener en cuenta las perspectivas adoptadas por los Estudios de la Cultura Visual y del Construccionismo Social ya que vivimos en una contemporaneidad compleja, cambiante, dónde una mezcla de sentidos y significados propios de cada cultura comparten los mismos espacios tiempos y dónde la mirada crítica, consciente y que pone en cheque las verdades aceptadas pueda favorecer un desarrollo humano más libertador.

Caminando por entre los saberes híbridos y transdisciplinares, poniéndose a pensar sobre la escolarización y las imposiciones a los niños y niñas, adolescentes y jóvenes, al disciplinamiento frente al mundo y los conceptos que desearon mejor comprender para más bien pensar la formación y la educación contemporánea son caminos que urgen en este sentido.

Aprender desde lo que una ha aportado a partir de sus recuerdos y relatos puede favorecer la construcción de una educación más significativa y llena de conexiones ante el abanico de temas que se nos ofrece el mundo actual. Basado en las propias experiencias vivenciales, donde las construcciones identitarias de las estudiantes se mezclaron con lo que tenían como tema de interés en una investigación académica refuerzan la idea de que es posible conectar lo particular a lo académico en la Universidad. Asimismo, construir experiencias de participación colaborativa y de indagación se insieren en una perspectiva más abierta a las necesidades actuales e invitan a reflexionar sobre lo qué significa pensar estas experiencias de participación y colaboración dentro de estas perspectivas y sus efectos en las relaciones de aprendizaje.

Compartir las responsabilidades, las decisiones, las planificaciones, la organización y la forma de evaluar lo desarrollado dedicando espacios y tiempos de aprendizaje respectando el tiempo de cada una se hizo imprescindible para que las estructuras vigentes en el medio académico pudieran tener en cuenta otra lógica a la hora de plantear una investigación. 
Poder transitar entre los tiempos y los espacios de manera performática, recogiendo lo que se presenta desde otras lógicas, estas investigaciones no partieron de indagaciones calcadas en el simples activismo, pero mas allá del simples labor, están conectadas a procesos de indagación, de investigación y de participación activa, del sentimiento de "dar cuenta" de una nueva narrativa en qué todas están incluidas y puedan encontrar su espacio a el aprendizaje.

Desde la óptica del Construccionismo Social los relatos construidos y las conexiones de los proyectos con lo local, lo personal y lo vivido como una característica muy fuerte (el entorno y el contexto) y la preocupación para que los proyectos realmente compartan con las ideas desde cada una son algunos ejemplos. Lo que han hecho las estudiantes ha prestado la atención a los procesos ordinarios de la vida cotidiana en el contexto de los proyectos de indagación problematizando las comprensiones más comunes y los hechos de la experiencia a través de preguntas. Estas preguntas puestas en relación a los marcos teóricos recogidos y a los debates desarrollados en el aula y en el Espacio Virtual sirvieron para que los Proyectos pudiesen cobrar sentido y significado.

A la luz de la perspectiva Construccionista de los Estudios de la Cultura Visual la inclusión del cine como una herramienta a la experiencia estética y performática de ver y acercarse a la cuestión principal (el aprendizaje desde la indagación) me han permitido establecer algunos puntos relevantes en este contexto. Este ideario que comparte campos híbridos y adisciplinares en que el conocimiento se da a partir de las relaciones y conexiones entre el sujeto y el mundo a partir de las distintas concepciones de la realidad (que hace parte de la cultura) creo no encontrarían en otra perspectiva de estudio esta apertura. Lo relacional, lo afectivo, lo personal y lo social ubicado a los conceptos que hubieron ser tratados en los Proyectos de Indagación se nos comparten además de micronarrativas también las representaciones sociales y los roles a que estamos sometidos en nuestros entornos sociales.

De esta manera, la experiencia de aprender de forma compartida y de colaboración con/entre todas me ha posibilitado otra lógica de investigar, desde un posicionamiento más cercano, personal y significativo y que conecta, explora y vincula distintas maneras de ver y construir el saber pedagógico. Aprender desde la Indagación es quizás el punto más alto de este recogido.

Para finalizar, como nos decía Fernando en su relato: "comenzamos la aventura de aprender desde nuestras experiencias, con el cine en la maleta" y luego lo que sucedió fue que se recorrió un camino repleto de distintos puntos de vista que se fue 
construyendo en la medida de que las ideas se iban añadiendo. El espacio del aula como un espacio de cambios e indagaciones en que los temas, contenidos y asuntos fueron organizados y decididos por las estudiantes que construían su propia historia desde sus miradas fue también dónde se han despertado el interés y motivación por emprender procesos formativos en la academia que no comparten con lo inmutable. Por lo contrario, establecen nuevas relaciones en que el sentimiento de transgresión, de romper con las estructuras rígidas por una pedagogía más flexible.

De misma manera, creo que estos Proyectos de Trabajo y de Indagación en un contexto de formación de profesores pudo favorecer una rara experiencia de aprendizaje en que no hay un currículo alejado de las vidas de las estudiantes, pero un momento de cambios profundos y significativos. Hablar del curriculum en esta experiencia no es tratar de una signatura cerrada y fija, pero desde qué esté puesta en relación "con" y "entre" crea otras relaciones de aprendizaje.

Desde aquí, queda el deseo de incrementar al profesorado experiencias para trabajar dentro de procesos que faciliten aproximaciones entre lo personal y lo académico como lo que he/mos desarrollado y donde las definiciones de las jerarquías se diluyan y todas estén al mismo nivel para aprender y enseñar a la vez.

Al fin y al cabo, ¿qué significa aprender a partir de los Proyectos de Indagación? A mí me parece que el aprendizaje que parte de la indagación puede lograr un sentido mucho mayor en la medida que se construye desde las relaciones establecidas entre las ideas particulares y lo que se puede conectar a lo científico. Partir de las dudas para plantear lo que se desea aprender muestra un universo de enfoques y perspectivas que pueden llevar a distintas maneras de entender el mundo y la realidad.

\section{Referencias}

FRESQUET, A. Imagens do desaprender: uma experiência de aprender com o cinema. Rio de Janeiro, UFRJ, 2007.

GIROUX, H. Cine y entretenimiento: elementos para una crítica política del filme. Barcelona: Paidós, 2003.

HERNÁNDEZ, F. La investigación basada en las artes: propuestas para repensar la investigación en educación. Educatio Siglo XXI, 26, pp. 85-118, 2008. 
Catadores da Cultura Visual: uma proposta para uma nova narrativa educacional. Porto Alegre: Mediação, 2007.

Transgressão e mudança na educação: os projetos de trabalho. Porto Alegre: Artmed, 2000.

Cultura visual, mudança educativa e projeto de trabalho. Porto Alegre: Artes Médicas, 1998.

KENNETH GERGEN (2008). Conferencia. Acceso en http://www.youtube.com/watch? $\underline{v}=$ J $5 a Q q I M W N 0 \&$ feature $=$ related

\section{Películas}

CANTET, L. Entre les Murs (filme cinematográfico). Sony Pictures Classics, Francia, 2008.

FLECK, R. Half Nelson (filme cinematográfico). Thinkfilm, USA, 2006

LAGRAVENESE, R. Freedom Writers (filme cinematográfico). Paramount Pictures, USA, 2007.

MAKHMALBAF, H. Buda az sharm foru rikht (tradución en español: Buda Explotó por vergënza) (filme cinematográfico) Irán, 2007

NEWELL, M. Mona lisa Smile (filme cinematográfico). Columbia Pictures, USA, 2003. 